\title{
Introducing barley as aphid reservoir in sweet-pepper greenhouses: Effects on native and released hoverflies (Diptera: Syrphidae)
}

\author{
Ana PINEDA and María Ángeles MARCOS-GARCÍA* \\ Biodiversity Research Institute CIBIO, University of Alicante, Campus San Vicente del Raspeig, 03080 Alicante, Spain; \\ e-mails: ana.pineda@ua.es; marcos@ua.es
}

Key words. Banker plants, biological control, Episyrphus balteatus, greenhouses, open-rearing systems, Sphaerophoria rueppellii, Syrphidae

\begin{abstract}
Habitat management is a form of conservation biological control, that includes strategies such as the provision of alternative prey for natural enemies. One example is the "banker plants" strategy, which consists of introducing cereals with aphids in horticultural crops. It is usually combined with parasitoid releases. In this work we evaluated whether aphid-infested barley as "banker plants" enhances native populations of aphidophagous syrphids and extends the residence time of Episyrphus balteatus (De Geer) following release. The work was performed in four replicated sweet-pepper commercial greenhouses in the southeast of Spain. Barley was sown, and infested with the aphid Rhopalosiphum maidis (Fitch). Visual censuses were performed to record released individuals of E. balteatus (marked on the thorax before release) and naturally occurring hoverflies. At the end of the experiment leaf samples were taken to the laboratory, and the immature syrphids were reared for identification. The occurrence of syrphids that come from outside the greenhouse was significantly increased by the presence of the infested barley plants. From a total of 506 observations of adult native syrphids, $81 \%$ were Sphaerophoria rueppellii (Wiedemann). We did not find significant differences between control plots and those provided with banker plants in their probabilities to retain released specimens of $E$. balteatus. Of the syrphids collected at immature stages from the barley leaves, we did not record any E. balteatus, and 100\% of the specimens were identified as S. rueppellii. We conclude that the banker plant strategy is effective in attracting natural populations of syrphids into sweet pepper greenhouses, but not in keeping released individuals of E. balteatus in the greenhouses long enough to lay eggs. We suggest that the E. balteatus release method should be amended.
\end{abstract}

\section{INTRODUCTION}

Aphids (Hemiptera: Aphididae) are very destructive and often dominant pests in sweet pepper greenhouses (Ramakers, 2004). In integrated pest management systems and especially in organic farming, preventative measures are the highest priority of pest control (Zehnder et al., 2007). Such measures include inoculative releases of natural enemies, beginning early in the crop season. A major challenge of this strategy is to establish such natural enemies in the crop in advance of pest invasion, when prey/host insects are absent, or at low numbers. This early period is focus of this study.

Habitat management is a form of conservation biological control that alters habitat to improve availability of the resources required by natural enemies for optimal performance (Landis et al., 2000). Provision of alternative prey is one form of habitat management. The use of "open-rearing" systems or "banker plants" consists of introducing cereals infested with aphids in horticultural crops. The aphids are not a threat to the crop, but they serve as alternative food for specific aphid natural enemies that also attack pest aphids infesting the crop. This approach has been used successfully for the control of Myzus persicae Sulzer and of Aphis gossypii Glover. In such studies, the use of open rearing units aids the establishment of the released natural enemies, including
Aphidius colemani Viereck (Hymenoptera: Aphidiidae), A. matricariae Haliday and Aphidoletes aphidimyza (Rondani) (Diptera: Cecidomyiidae) (Hansen, 1983; Bennison \& Corless, 1993; Jacobson \& Croft, 1998). The effect of such open rearing units on natural populations, however, has not been previously studied in horticultural crops.

The larvae of some syrphid species are aphid predators that are important as biological control agents (e.g. Chambers \& Adams, 1986, Rojo et al., 1996). Syrphid larvae are often the most abundant aphid predators in outdoor crops (Niehoff \& Poehling, 1995; Jansen, 2000; Miñarro et al., 2005), particularly at lower temperatures that are unsuitable for other aphidophagous predators, such as ladybirds. Several syrphid species can naturally occur in Mediterranean greenhouses (Pineda \& Marcos-García, 2006). However, the only species that is commercially available is Episyrphus balteatus (De Geer). In sweet pepper greenhouses in the southeast of Spain, this species is abundant, accounting for up to $30 \%$ of the syrphid captures (Pineda \& Marcos-García, 2006). In this region, most greenhouses are made of plastic instead of glass, from which insects can ready escape. We have observed in previous preventive releases of this species that it does not remain in the greenhouse long enough to lay eggs.

Here evaluate the potential of banker plants as aphid reservoirs (1) to enhance natural populations of syrphid,

\footnotetext{
* Corresponding author.
} 
and (2) to increase the residence time of E. balteatus release into greenhouses.

\section{MATERIAL AND METHODS}

\section{Experimental site}

The study was conducted in four commercial greenhouses of sweet pepper located on Pilar de la Horadada (Alicante). This region of southeast Spain near the Mediterranean coast is a traditionally agricultural zone (Campo de Cartagena). In this region, the sweet pepper is planted in December-January and is grown until July-August under an integrated pest management system. The study was performed from 25 May to 4 June 2006, when aphidophagous syrphids were at peak numbers in this area (Pineda \& Marcos-García, 2006). All the greenhouses were of the type "Almería"; a wooden structure covered by thermal polyethylene, with a screen net in the lateral openings. During the experimental period, both the side walls (screen nets) and the ceiling windows of the greenhouses were completely open during the day for ventilation, so that insects from outside could either enter or escape from both the experimental and control plots.

The four greenhouses were divided with an anti-thrips screen net to create two plots of equal surface area (ca. $500 \mathrm{~m}^{2}$ ). In one plot in each greenhouse (Fig. 1), three months before the experiment, barley seeds were sown in patches of $25 \mathrm{~cm}$ of diameter (ca. 100 seeds per patch) by hand, at a rate of 3 patches per 100 $\mathrm{m}^{2}$. The other plots acted as control without barley patches. In a preliminary bioassay we tested the effectiveness of the antithrips net in isolating the plots, by marking adult syrphids in each plot with a distinctive colour. No movements of marked syrphids were observed between plots, or between greenhouses. During the experiment, the sweet pepper plants were free of aphids, in order to simulate the conditions of preventive releases. Barley (Hordeum vulgare L.) was infested twice (one month and two months before the experiment) with the aphid Rhopalosiphum maidis (Fitch), collected from natural populations in the field. These aphid colonies were similar between plots and among greenhouses since all the banker plants were infested on the same days and with a similar number of aphids.

\section{Adult records}

Pupae of E. balteatus were purchased from a commercial producer. When adults were 1-day old, they were marked on the thorax with a water-based paint (Decorfin ${ }^{\circledR}$ ) and transferred to the plots the next day. These adults were released into each plot at a rate of 20 adults per $500 \mathrm{~m}^{2}$ ( 8 males and 12 females $)$. This is ten times higher than the recommended rate. We released at such high rate because in a preliminary experiment in which a lower number was released, the probability of detecting the syrphids was very low, even when they were present in the greenhouses. Visual censuses of $15 \mathrm{~min}$ duration (enough time to walk along the whole plot) were performed in a randomized order. Censuses were performed twice a day (morning and afternoon, around 8:00 and 16:00 h) every other day over a 12-day period (i.e. 6 sample days in total). The censuses for all treatments consisted of walking between every two lines of pepper plants, and shaking them simultaneously. All syrphids observed (including unmarked individuals that came into the greenhouses) were counted and the species identity and marking (when present) were recorded.

\section{Larval records}

At the conclusion of censuses for syrphid adults, samples of barley were collected to record the immature syrphids present on the aphid reservoirs. In each plot, seven barley patches were randomly selected, and a single sample of five leaves from each

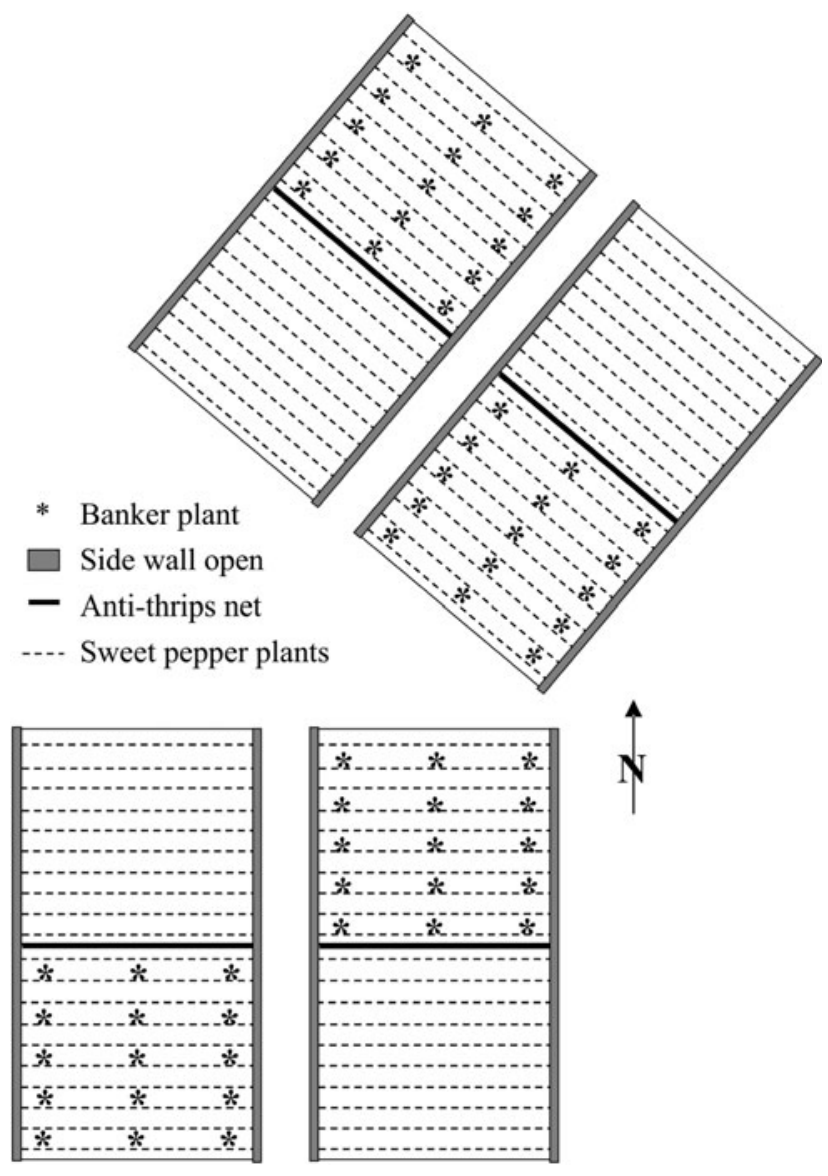

Fig. 1. Lay-out of the experimental greenhouses, with divisions and spatial distribution of the "banker plants" indicated (barley patches of $25 \mathrm{~cm}$ of diameter, at a rate of 3 patches per $100 \mathrm{~m}^{2}$.

patch was placed in a rearing cage and transferred to the laboratory. Immature syrphids were identified in these samples and reared until adults emerged, to confirm the identification by the authors.

\section{Statistical analysis}

A general linear model (GLM) with repeated measures was used to determine the effect of the introduction of banker plants on natural populations of syrphids (i.e., syrphids that entered the greenhouses from the outside). Sampling day and time of day were set as within-group factors, and the banker plants and greenhouse as between-group factors, customizing the model to show the main effects of their interaction. Data satisfied the assumptions of sphericity (Mauchly) and homogeneity of variances (Levene).

We used survival analysis or "failure time analysis" (Muenchow, 1986) to analyze the residence time of marked adults of E. balteatus released in control plots and in banker plant plots. This analysis addresses data of the form "time until an event occurs", which in this case was when, in a plot, none of the marked E. balteatus were recorded. We used the Kaplan-Meier product-limit nonparametric method for the computation of the probability that released E. balteatus specimens are observed in a plot during a 15 min census ("survival"). Then the logrank (Mantel-Cox) statistic was applied to test differences between plots with and without banker plants. To compare the mean residence time, the non-parametric Wilcoxon test for related samples was used because of the non-normality of the data even 


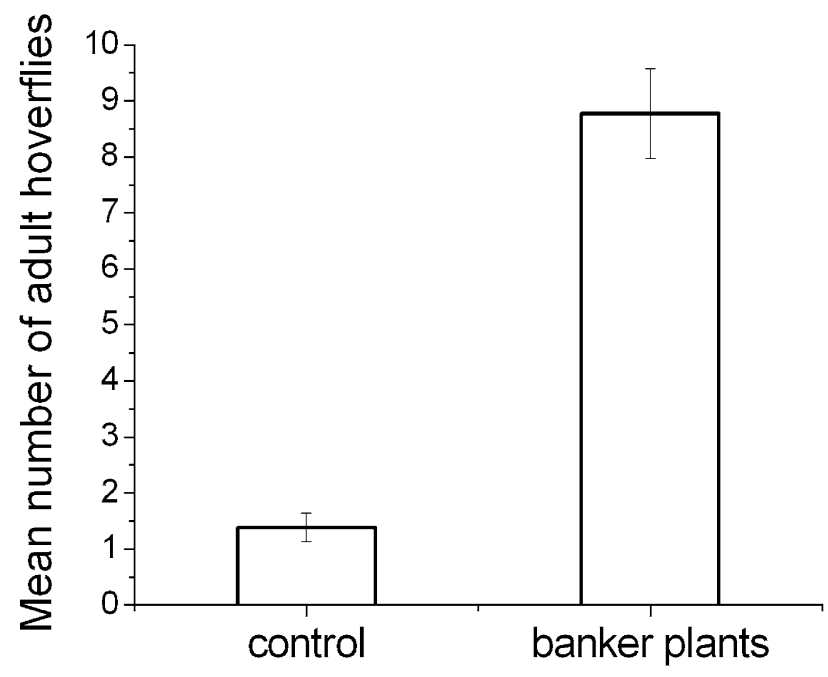

Fig. 2. Mean ( \pm standard error) number of naturally occurring adult syrphids observed per census in greenhouse plots with or without banker plants during the 10-day period following release of marked syrphids.

following common transformations. All data were analyzed with the SPSS statistical package (SPSS, 2004).

\section{RESULTS}

\section{Native populations}

The number of naturally occurring (vs. purposefully released) adult syrphids (Fig. 2) found in experimental plots was significantly higher than in control plots $(\mathrm{F}=$ 24.14 , df $=1, P=0.004)$. No significant differences were found between the six days of sampling $(\mathrm{F}=2.24$, $\mathrm{df}=$ 2.12, $P=0.15)$, between morning and afternoon sampling $(\mathrm{F}=0.02, \mathrm{df}=1, \mathrm{p}=0.9)$, or between individual greenhouses $(\mathrm{F}=1.47$, $\mathrm{df}=1, P=0.28)$.

Adults of four hoverfly species (Table 1 ; total $\mathrm{n}=506$ ) were recorded as entering on their own and occurring in the sweet pepper greenhouses: Sphaerophoria rueppellii (Wiedemann) (81\%), Eupeodes corollae (Fabricius) (14\%), Episyrphus balteatus (2\%), Sphaerophoria scripta (Linnaeus) (2\%). Four adult specimens of the genus

TABLE 1. Species composition of syrphids occurring in sweet pepper greenhouses, including total number and percentage of adults colonizing from outside the greenhouses (as recorded during all visual census), and of larvae and pupae that were collected from barley samples (as described in the text).

\begin{tabular}{lccccc}
\hline \multirow{2}{*}{ Species } & \multicolumn{2}{c}{ Adults } & & \multicolumn{2}{c}{$\begin{array}{c}\text { Larvae and } \\
\text { pupae }\end{array}$} \\
\cline { 2 - 3 } \cline { 5 - 6 } & $\mathrm{n}$ & $\%$ & & $\mathrm{n}$ & $\%$ \\
\hline Released E. balteatus (marked) & 174 & - & & 0 & 0 \\
Native populations & & & & & \\
$\quad$ Sphaerophoria rueppellii & 412 & 81 & & 44 & 100 \\
Eupeodes corollae & 72 & 14 & & 0 & 0 \\
Episyrphus balteatus & 9 & 2 & & 0 & 0 \\
Sphaerophoria scripta & 9 & 2 & & 0 & 0 \\
$\quad$ Paragus spp. & 4 & 1 & & 0 & 0 \\
Total (native) & 506 & 100 & & 44 & 100 \\
\hline
\end{tabular}

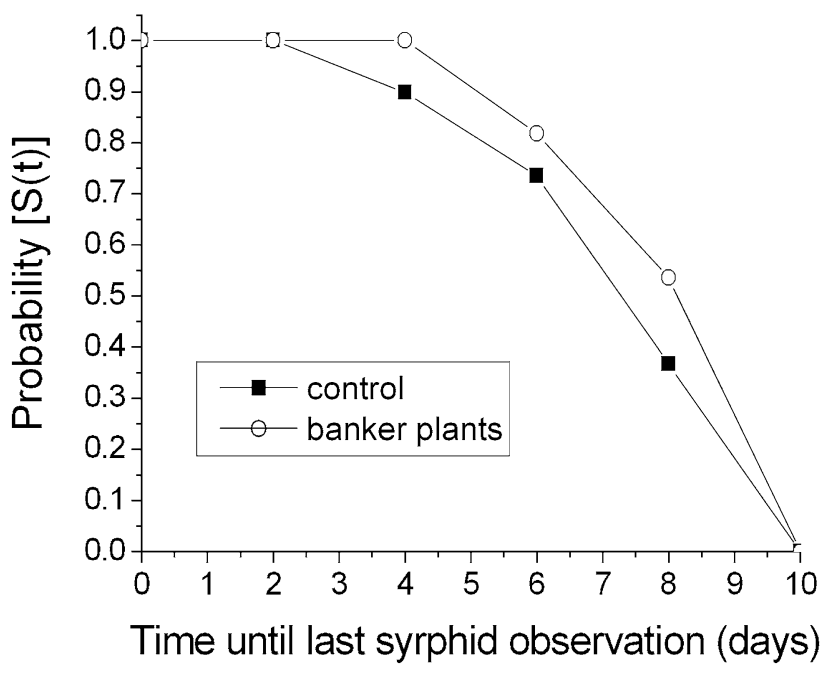

Fig. 3. Comparison between plots with and without banker plants in their probability of retaining released specimens of $E$. balteatus, as observed during 15-min observation periods over a 10 -day period following release. $\mathrm{S}(\mathrm{t})$ is the probability that at least one specimen is observed.

Paragus Latreille were observed (1\%) while flying; however, species identification was not possible. From larval sampling, a total of 44 larvae recorded, all of which (100\%) were $S$. rueppellii. No larvae of the released species, E. balteatus were recorded.

\section{Released $E$. balteatus}

We did not find significant differences between plots with and without banker plants in their tendencies to retain released specimens (Wald statistic $=0.89, \mathrm{df}=1, P$ $=0.35$; Fig. 3 ). We recorded only as many as 37 marked E. balteatus (all greenhouses combined) during a single censuring period of the 160 specimens released. The maximum residence time recorded was 8 days, which was observed in only two plots.

\section{DISCUSSION}

Our results confirm that the provision of aphid reservoirs with the banker plant strategy in sweet-pepper greenhouses leads to an increase of naturally occurring aphidophagous hoverflies in these greenhouses. Previous studies have demonstrated the effectiveness of this strategy to build up released aphidophagous insect populations before aphids arrive on the crop (Hansen, 1983; Bennison, 1992; Bennison \& Corless, 1993; Jacobson \& Croft, 1998). However, the current work is the first that focuses on natural populations of natural enemies, instead of released specimens. Additionally this is the first work on this strategy involving syrphids.

Regarding the effect of the open rearing units on released E. balteatus, we can conclude that their use does not aid the establishment of this species, since no larvae were observed on the collected samples of barley. This is because the mean residence time observed with banker plants was 5.8 days, and the minimum time that E. balteatus needs to be gravid is around 7 days (Geusen-Pfister, 1987). E. balteatus larvae were abundant 
in banker plants from other greenhouses, and it has been recorded preying on $R$. maidis several times (Rojo et al., 2003).

Previously to this study, we observed that syrphid natural populations occur in sweet pepper greenhouses without applying any strategy of conservation biological control (Pineda \& Marcos-García, 2006). We also found (data in prep.) a high proportion of sweet pepper pollen in the syrphid gut content, during the period when syrphids were most abundant in the area (April, May, and June), suggesting that sweet pepper is a suitable pollen source for syrphids. Nevertheless we did not study if sweet pepper nectar is suitable for their reproduction, but it is known that syrphid adults can also use aphid honeydew as a carbohydrate source (van Rijn et al., 2006; Hogervorst et al., 2007). In another work we introduced additional floral resources in the greenhouses to increase the residence time of released E. balteatus (Pineda \& Marcos-García, 2008), but it did not increase significantly. With the "banker plant" strategy we add the aphid stimulus, but once again the time E. balteatus stays in the greenhouses is not long enough to increase their population. As a conclusion from our results, for Mediterranean greenhouses with a low level of isolation, we strongly recommend changing the release methodology of $E$. balteatus. To have a quicker response, instead of releasing pupae we suggest to release eggs, or first-instar larvae, since Wyss et al. (1999) found this method effective to control aphids in semi-field conditions. If a local production of syrphids is available, the release of gravid females could be another useful alternative.

Aphid populations present on the barley were decreasing along the experimental time, because of the control exerted by the natural enemies. The maintenance of the open rearing units is essential for their effectiveness (Bennison \& Corless, 1993; Jacobson \& Croft, 1998). Some aspects that need to be considered are: (1) to establish the banker plant system at the beginning of the crop season, (2) to inoculate with aphids several times to keep the aphid population, (3) to distribute them at least at 20 locations per $1000 \mathrm{~m}^{2}$, (4) to observe carefully the phytosanitary status of the barley.

The banker plant system has only been employed previously with the aphid Rhopalosiphum padi L. (Bennison \& Corless, 1993; Jacobson \& Croft, 1998). We worked with $R$. maidis because it was the species found in greenhouse conditions in our study area. Both aphids are easily parasitized by Aphidius colemani. This is the most commonly released aphid parasitoid, and it is effective on controlling small aphids such as Myzus persicae or Aphis gossypii, which are major pests in sweet pepper greenhouses (unpubl. data). On the other hand, for "big aphids" such as Macrosiphum euphorbiae or Aulacorthum solani, releases of Aphidus ervi or Aphelinus abdominalis are recommended (Rabasse \& van Steenis, 1999). The combination of barley with other aphid species in a banker plant system may be useful to control a wide range of pest species and needs to be further studied.
ACKNOWLEDGEMENTS. We are very grateful to the farmer J. Muñoz for the permit to use his greenhouses. We also thank N. Pérez from the University of Leon for the aphid identification. Thanks also to A. Comley for his help with the language correction. Financial support was provided by the Ministerio de Ciencia y Tecnología, INIA ( ${ }^{\circ}$ RTA03-101-C2), and by the Generalitat Valenciana for the studentship of A. Pineda. (CTBPRB/2004/081).

\section{REFERENCES}

BENNISON J.A. 1992: Biological control of aphids on cucumbers: use of open rearing systems or "banker plants" to aid establishment of Aphidius matricariae and Aphidoletes aphidimyza. Med. Fac. Landbouww. Univ. Gent 57(2b): 457-466.

Bennison J.A. \& Corless S.P. 1993: Biological control of aphids on cucumbers: further development of open rearing units or "banker plants" to aid establishment of aphid natural enemies. IOBC/WPRS Bull. 16(2): 5-8.

Chambers R.J. \& Adams T.H.L. 1986: Quantification of the impact of hoverflies (Diptera: Syrphidae) on cereal aphids in winter wheat: analysis of field populations. J. Appl. Ecol. 23: 895-904.

Geusen-Pfister H. 1987: Studies on the biology and reproductive capacity of Episyrphus balteatus Deg. (Dipt., Syrphidae) under greenhouse conditions. J. Appl. Entomol. 104: 261-270.

HANSEN L.S. 1983: Introduction of Aphidoletes aphidimyza from an open rearing unit for the control of aphids in glasshouses. IOBC/WPRS Bull. 10: 62-65.

Hogervorst P.A.M., Wäckers F.L. \& RomeIs J. 2007: Detecting nutritional state and food source use in field-collected insects that synthesize honeydew oligosaccharides. Funct. Ecol. 21: 936-946.

JACOBSON R.J. \& CROFT P. 1998: Strategies for the control of Aphis gossypii Glover (Hom.: Aphididae) with Aphidius colemani Viereck (Hym.: Braconidae) in protected cucumbers. Biocontr. Sci. Technol. 8: 377-387.

JANSEN J.P. 2000: A three-year field study on the short-term effects of insecticides used to control cereal aphids on plantdwelling aphid predators in winter wheat. Pest Manag. Sci. 56: 533-539.

Landis D.A., Wratten S.D. \& GurR G.M. 2000: Habitat management to conserve natural enemies of arthropod pests in agriculture. Annu. Rev. Entomol. 45: 175-201.

Miñarro M., Hemptinne J.L. \& Dapena E. 2005: Colonization of apple orchards by predators of Dysaphis plantaginea: sequential arrival, response to prey abundance and consequences for biological control. BioControl 50: 403-414.

Muenchow G. 1986: Ecological use of failure time analysis. Ecology 67: 246-250.

Niehoff B. \& Poehling H.-M. 1995: Population dynamics of aphids and syrphid larvae in winter wheat treated with different rates of pirimicarb. Agric. Ecosyst. Environ. 52: 51-55.

Pineda A. \& Marcos-García M.A. 2006: First data on the population dynamics of aphidophagous syrphids in Mediterranean pepper greenhouses. IOBC/WPRS Bull. 29: 169-174.

Pineda A. \& Marcos-García M.A. 2008: Evaluation of several strategies to increase the residence time of Episyrphus balteatus (Diptera, Syrphidae) releases in sweet-pepper greenhouses. Ann. Appl. Biol. DOI 10.1111/j.1744-7348.2008. 00215.x.

Rabasse J.-M. \& van Steenis M.J. 1999: Biological control of aphids. In Albajes R., Gullino M.L., van Lenteren J.C. \& Elad Y. (eds): Integrated Pest and Disease Management in Green- 
house Crops. Kluwer Academic Publishers, Dordrecht, pp. 235-243.

Ramakers P.M.J. 2004: IPM Program for sweet pepper. In Heinz K.M., Van Driesche R.G. \& Parrella M.P. (eds): Biocontrol in Protected Culture. Ball Publishing, Batavia, pp. 439-456.

Rijn P.C.J. van, KoOIJMAn J. \& WÄcKers F.L. 2006: The impact of floral resources on syrphid performance and cabbage aphid biological control. IOBC/WPRS Bull. 29: 149-152.

Rojo S., Hopper K.R. \& Marcos-García M.A. 1996: Fitness of the hoverflies Episyrphus balteatus and Eupeodes corollae faced with limited larval prey. Entomol. Exp. Appl. 81: $53-59$.
Rojo S., Gilbert F., Marcos-García M.A., Nieto J.M. \& Mier M.P. 2003: A World Review of Predatory Hoverflies (Diptera, Syrphidae: Syrphinae) and Their Prey. CIBIO, Alicante, 319 pp.

Wyss E., Villiger M. \& MÜller-Schrärer H. 1999: The potential of three native insect predators to control the rosy apple aphid, Dysaphis plantaginea. Biocontrol 44: 171-182.

Zehnder G., Gurr G.M., Kuhne S., Wade M.R., Wratten S.D. \& Wyss E. 2007: Arthropod pest management in organic crops. Annu. Rev. Entomol. 52: 57-80.

Received September 18, 2007; revised and accepted January 15, 2008 